\title{
The short - term nephropathological complications due to alloxan induction of diabetes mellitus in male rabbits
}

\author{
H. Kh. U. Al-Karagoly \\ Coll. of Vet. Med. / Unive. of Al-Qadisiya \\ K. F. AbdulKareem \\ Coll. of Pharmacy / Unive. of Basrah
}

\begin{abstract}
This study was conducted to assess the pathological changes in kidneys after twenty day from induction of diabetes mellitus in male rabbits.Sixteen male rabbits were used in this study and divided into two equal groups: diabetic group (Dm) and control group $(\mathrm{Cm})$. Diabetes mellitus was induced by i.v injection of alloxan monohydrate at dose rate $100 \mathrm{mg} / \mathrm{kg}$ dissolved in $1 \mathrm{ml}$ of normal saline. Blood was collected after three days to check fasting serum glucose.Serum glucose level was elevated starting from the $1^{\text {st }} 3$ days after induction of diabetes mellitus. The histopathological results revealed that there were: edema, glomerular hypertrophy and hypercellularity, as well as glomerular necrosis, glomerular swelling, glomerular congestion with glomerular cast and rupture. The conclusion that renal glomeruli and tubules affected progressively after short period from beginning of diabetes mellitus.
\end{abstract}

\section{Introduction}

Diabetes mellitus is a serious public health disease \& its prevalence has reached astronomical numbers. Experts forecast that in the year 2025, 9\% of the adult population will suffer from diabetes, increasing by $1.6 \%$ from the 1995 estimates (1). It is a major public health problem worldwide (2). Diabetes mellitus is a group of metabolic diseases characterized by hyperglycemia resulting from defects in insulin secretion, insulin action, or both (3).Four major types of diabetes have defined: type-1(insulindependent diabetes mellitus IDDM), type2 (non-insulin-dependent diabetes mellitus NIDDM), gestational diabetes mellitus (GDM) and diabetes secondary to other conditions (4).The Kidneys undergo renal hypertrophy and mild glomerular injury in

\section{Materials and Methods}

Sixteen rabbit (White Newzealand Rabbits) purchased from the local market, weighing 1.2-2 kg were used in the experiment. The animals were divided into two equal groups: Diabetic group (Dm) includes (8) rabbits and Control groups $(\mathrm{Cm})$ includes $(8)$ rabbits.

\section{Blood Collection:}

The blood was collected according to the following equation: Total blood volume $(\mathrm{TBV})=6 \%$ of lean body weight, maximum blood collection $=20 \%$ of total blood volume every two weeks. early stage and structural alterations of the proximal straight tubules at late stages during the acute phase of diabetes (5). Diffusely damaged proximal tubules had revealed in histological examination to the kidney of diabetic rat (6). The Bowman's capsules and glomeruli have affected as well as there is degenerative changes in the epithelial cells of urinifreous tubules (7). Short-lasting untreated disease is manifested microscopically by cloudy swelling, vacuolar degeneration ,proximal tubules cell steatosis ,basement membrane thickening and glycogen presence in Armani zone cells (8). This study was conducted to assess the pathological changes in kidneys after twenty day from induction of diabetes mellitus.

Animal weight in $\mathrm{kg} \times 0.06 \times 0.02 \times 1000=()$ ml. (9)

The blood collected at the following periods: Zero day (before the injection of alloxan), three days, ten days and twenty days after injection of alloxan. The blood was collected from marginal ear vein with empty stomach. The collected blood was centerfugated to obtain the serum. (10)

\section{Induction of Diabetes Mellitus:}

Diabetes mellitus had induced in over night fasting rabbits by a single injection of alloxan (alloxan monohydrate) at dose 
$100 \mathrm{mg} / \mathrm{kg}$ into marginal ear vein(11). The control groups were I.V injected with $1 \mathrm{ml}$ of $0.9 \%$ of normal slain. (12)

Estimation of Fasting Serum Glucose:

After 3 days of alloxan injection the animals were fasting overnight and bled for checking the hyperglycemia .Fasting serum blood glucose (FSG) was measured by using special kit, then the (FSG) concentrations were checked after 3 days and then every 10 days .

\section{Animal Sacrificed and Histopathological} Procedures:

Four rabbits (two from each were sacrificed each (10) days intervals. Tissue samples were taken from the kidney, fixed in $10 \%$ buffered formalin, embedded in paraffin, cut at $5 \mu \mathrm{m}$, stained with hematoxylin and eosin and examined by light microscopy(13 and 14).

Statistical Analysis:

The data were expressed as mean tstandard deviation (SD) and analyzed using analysis of variance (ANOVA).

The histopathological changes: Fasting Serum Glucose Concentrations (FSG):

On day zero, the results revealed no significant differences between the groups
(Dm and $\mathrm{Cm}$ ). On day ten after alloxan injection there were significant differences between diabetic and control groups $(\mathrm{P}<0.05)$. On day twenty the results revealed significant differences between diabetic and control groups $(\mathrm{P}<0.05)$.

Weights of kidneys:

Right kidney: on days ten and twenty there were no differences $(\mathrm{P}<0.05)$ among all groups.

Left kidney: on day ten and twenty there were no significant differences $(\mathrm{P}<0.05)$ between all groups.

Animals Body Weights: on zero day there were no significant differences between the groups. On $1^{\text {st }}, 2^{\text {nd }}$ and $3^{\text {rd }}$ weeks the results revealed significant differences between diabetic (the body weights were decreased in these groups) and control groups (the body weights in these groups were increased) $(\mathrm{P}<0.05)$.

\section{Kidney:}

The results revealed that after ten days from alloxan injection diabetes led to edema, hypertrophy and hypercellularity of glomeruli, without any cast or inflammation. 


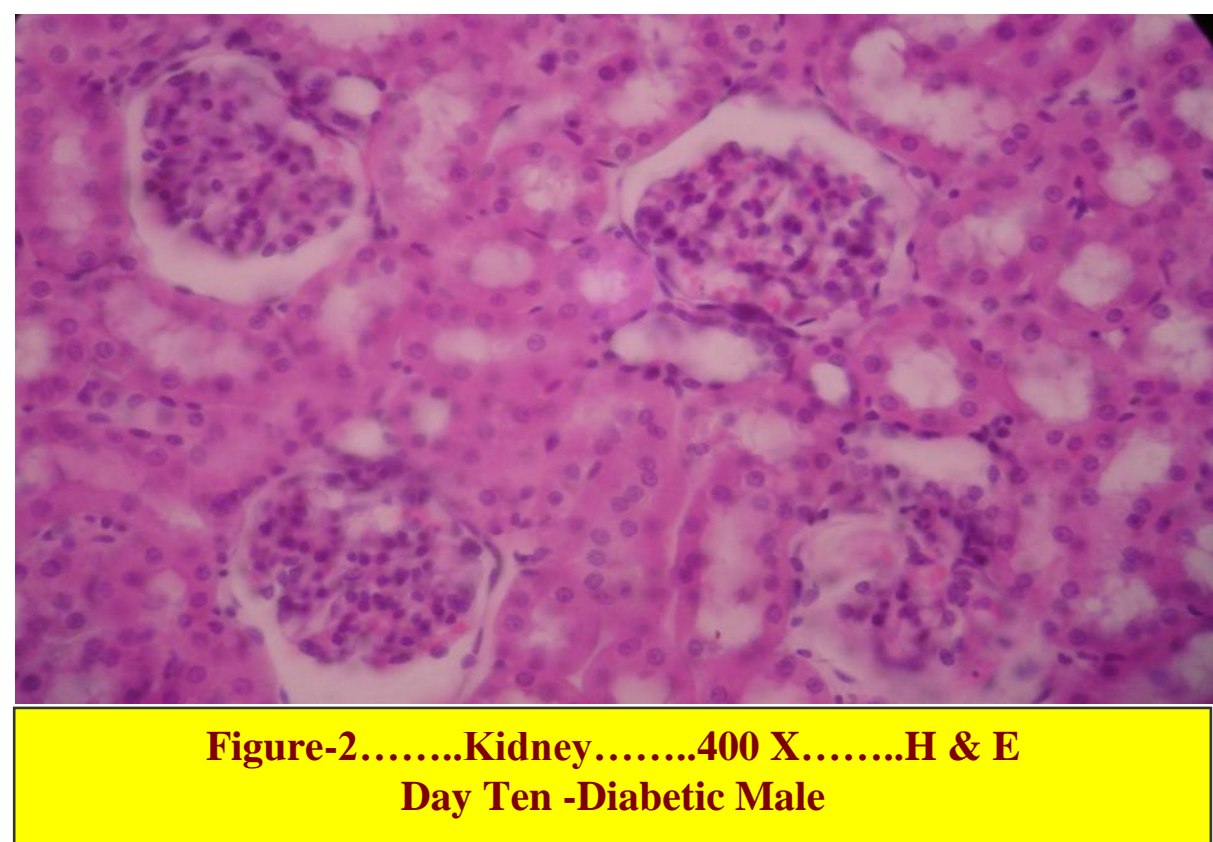

1. Edema.

2. Hypertrophy and hyper cellular of glomeruli without any cast or inflammation.

3. Dilatation of renal convoluted tubules.

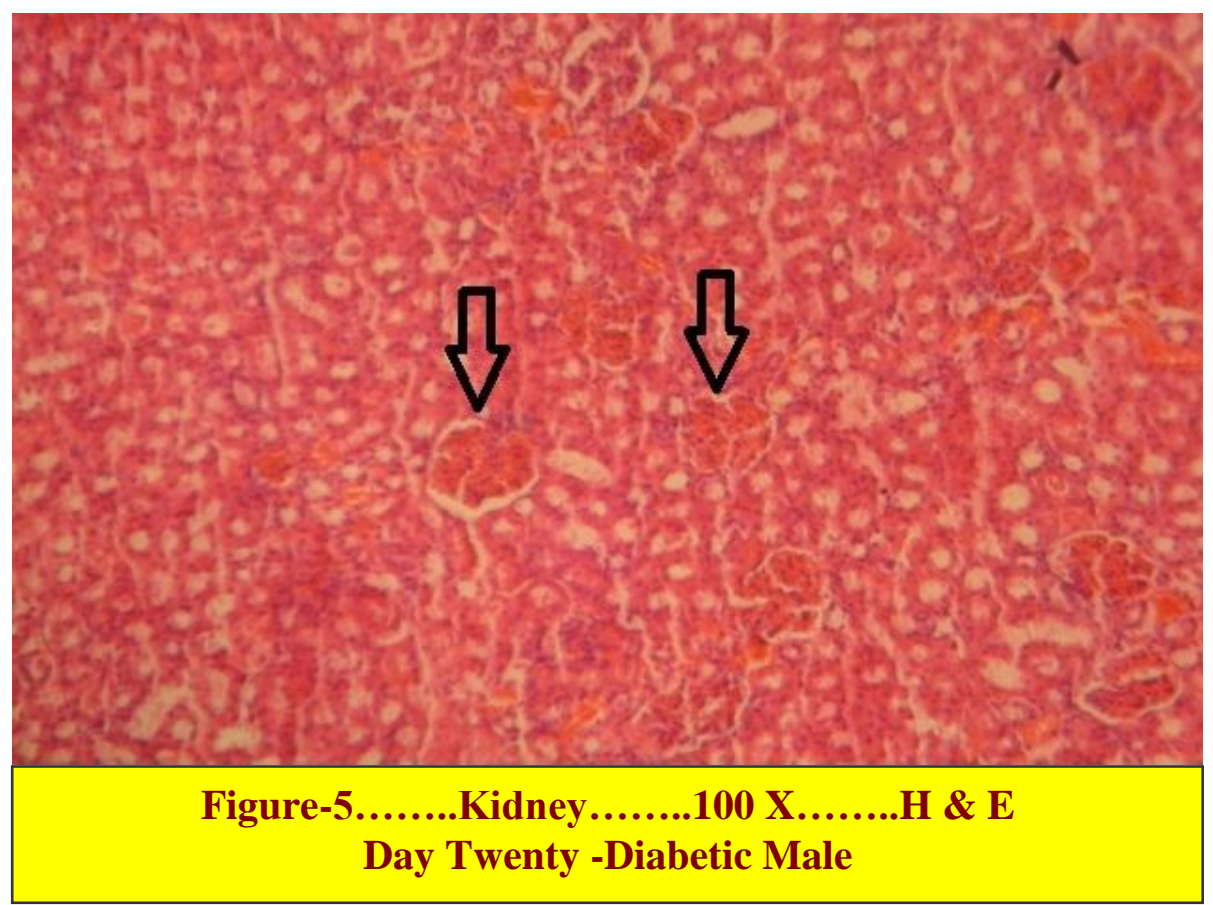

1. Glomerular congestion \& necrosis (deeply eosinophilic). ( Arrows) 


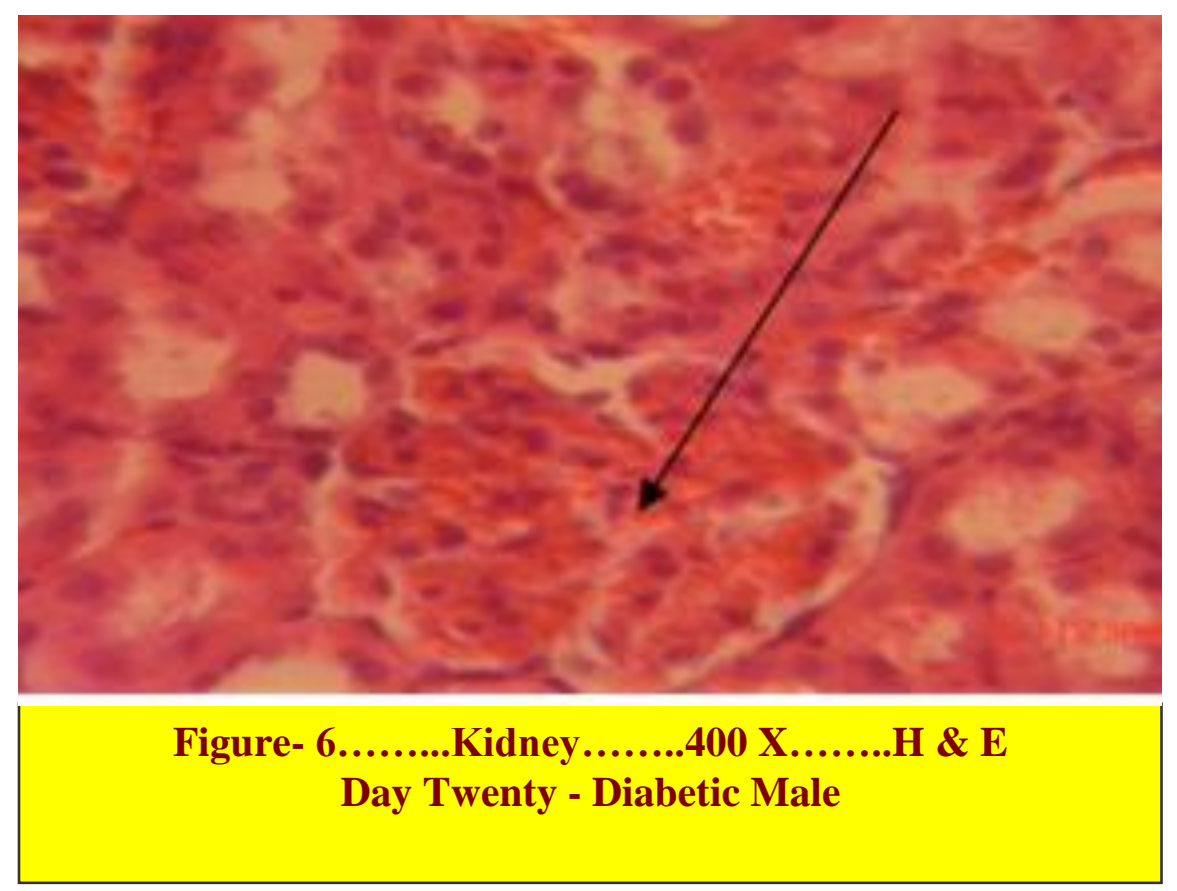

1. Glomerular necrosis (deeply eosinophilic). (Thin arrow).

\section{Glomerular swelling.}

\section{Glomerular congestion \& rapture.}

\section{Discussion}

The study revealed a significant difference in serum glucose concentrations between the periods of the experiment as there was progressive increase in the serum glucose levels; this is similar to the results of (14) and (15). Alloxan acts on the insulin- producing pancreatic ß-cells within islets of Langerhans that are selectively destroyed by the oxidant production (16). Current evidence suggests that the selective cytotoxicity of alloxan is due to the function of three factors: efficient uptake, oxidant production by coupling of drug with intracellular reluctant (ascorbate and thiols) coupled with low levels of glutathione peroxidase in the islets (12). Alloxan has similar structure to glucose and therefore is selectively taken by $\beta$-cells (17). The histopathological results revealed that on day ten and twenty the changes include: edema, glomerular hypertrophy and hypercellularity. Our results were in accordance with other, who mentioned that the changes in renal structure include nephromegaly and glomerular enlargement (18). (19) Showed that the diabetic animals demonstrate lower weight gain, renal hypertrophy assessed by the left kidney weight and kidney/body weight ration as compared with control. (10) Revealed that wet kidney weight increased after onset of diabetes and reached a plateau by day 20 of diabetes and indicate that renal hypertrophy is well-known in the early stages of diabetes. (20) Indicate that after 14 weeks from induction of diabetes mellitus the kidney develops glomerulosclerosis by increasing the deposition of glomerular extracellular matrix. Diabetes mellitus is associated with oxidative stress (21). Damage caused by free radicals is possibly involved in betacell destruction and in the pathogenesis of diabetes mellitus and alterations of metabolic processes in diabetes influence enzymatic defenses, and these changes may be associated with late complications of diabetes (22). The most common oxygen radicals are superoxide (O), 
hydrogen peroxide (H2O2) and hydroxyl radical $(\mathrm{OH})$ (23 and 24). Whereas the ions superoxide and hydroxyl radicals are more reactive, $\mathrm{H} 2 \mathrm{O} 2$, which doses not possess the chemical structure of a radical, is more membrane permeable (25). The three main targets of oxygen radicals are lipids, proteins and DNA. Extensive lipid peroxidation in biological membranes causes alteration in fluidity, decreased membrane potential, increased

\section{References}

1.Levenduski, E. (2004). The Impact of Nutrition Education In A community- Based Diabetes Education Program. M.Sc. Thesis/ College of Human Sciences / The Florida state University.

2.Kothari, B.; Khinchi, A. \& Pareck, A. (2005). Prevalence of Diabetes Mellitus Amongst the Bhargavas in India. J.Hum.Ecol.17 (2):137141.

3.Noonan, W.T. \& Banks, R.O. (2000). Renal Function and Glucose Transport in Male and female Mice with Diet induced Type IIDiabetes Mellitus. P.S.E.B.M. 225: 221-230.

4.Harris, M. (2007). Descriptive epidemiology. $1^{\text {st }}$ ed. Chapter 1. National Institutes of Diabetes \& Digestive \& Kidney disease. PP:1-4.

5.Maeda, M.; Yabuki, A.; Suzuki, S.; Matsumoto, M.; Tanguchi, K. \& Nishinakagawas, H. (2003). Renal Lesions in Spontaneous Insulin- dependent Diabetes Mellitus in the Nonobese Diabetes Mouse: Acute phase of Diabetes. Vet Pathol. 40: 187195.

6. Koladka, T.M.; Finegold, M.; Moss, L. \& Woo, S.L. (1995). Gene therapy for diabetes mellitus in rats by hepatic expression of insulin. Proc.Natl.Acad.Sci. 92: 3293-3297.

7.Agurirre, J.; Han, J.; Itagaki, S. \& Doi, K. (1993). Lectin HistochemicalStudy on the Kidney of Normal permeability to hydrogen and other ions and eventual rupture of the cell, and there is considerable evidence suggesting that oxidative stress plays a role in tissue damage associated with diabetes. The source of this inappropriate oxidation is not known but could be related to an increase in the concentration of redox catalysts, and/or substances prone to peroxide and free radicals generation, such as monosaccharide (26). as mon

and Streptozotocin- Induced Diabetes Hamsters. Histology and Histopayhology, 8(2):273278.

8.Bartosikova, L.; Necas, J.; Suchy, V.; Kubinova, R.; Vesela, D.; Benes,L.; Bartosik, T.; Illek,J.; Salphachta, J.; Klusakova, J.;Bartosova, L.; Strnadova, V.; Frana, P. \& Franova, J.(2003). Monitoring of Anti oxidative Effect of Morine in Alloxaninduced Diabetes mellitus in the Laboratory Rat. Acta. Vet. Brno. (72): 191-200.

9.McGuill, M.W. \& Roman, A.N. (1989)."Biological Effects of Blood Loss: Implications for Sampling Volumes and Techniques". ILAR News, 31(4): 5-20.

10. Christopher, M.M. \& Neill, S. (2000). Effect of specimen collection and storage on blood glucose and lactate concentrations in healthy, hyperthyroid and diabetic cats. Veterinary Clinical Pathology, 29(1):22-28.

11. AL-Aumar, L.W.K. (1994). The effect Of Garlic on Blood Glucose and Cholesterol Level in Normal and Diabetic Rabbits. M.Sc thesis/ College of veterinary medicine/ University of Baghdad. [Arabic].

12. European Federation of Pharmaceutical Industries Association and the European Center for the Validation of Alternative Methods [EFPIA \& ECVAM]. (2000). A Good Practice Guide to 
the Administration of Substances \& Removal of Blood, Including Routes and Volumes. $J$ Appl Toxicol, 21 15-23.

13. Luna, L.G. (1968). Manual of Histological Staining methods of the Armed Forces Institute of Pathology. $3^{\text {rd }}$ ed. New York, Mc Graw-Hill.

14. Bancroft, J.D.; Stevens, A. \& Turner, D.R. (1990). Theory and Practice of Histological techniques. $3^{\text {rd }}$ ed. Churchill Livingstone.PP:21-226.

15. AL-Egeely, S.A.A. (1996). Effect of Experimental diabetes Mellitus on Severity of Acute Pneumonia Induced by Klebsiela pneumonia in Adult Rabbits. M.Sc. thesis/ College of veterinary medicine/ University of Baghdad. [Arabic].

16. AL-Mashhaddany, H.A.J. (1999). The Effect of Eucalyptus camaludensis Leaves extract on serum Glucose and Protein in Induced Diabetic Rabbits Experimentally. M.Sc thesis/ College of Veterinary medicine / University of Baghdad. [Arabic].

17. Silva-Sousa, Y.T.C.; Peres, L.C. \& Foss, M.C. (2003). Enamel hypoplasia in a litter of rats with alloxan- induced diabetes mellitus. Braz. Dent. J. 14(2):6569.

18. Tipson, R.S. (2006). Organic Syntheses: Alloxantin dehydrate. Coll., 4:25.

(http://www.rcpe.ac.uk/publiction s/articles/joutnal_32_2/L\%209Hi st Allox.pdf).

19. Pelley, J.W. (1997). Biochemistry. (ed). Mosby, A Times Mirror Company.PP:130-196.
20. Curran, R.C. \& Crocker, J. (2000). Curans Atlas of Histopathology. $4^{\text {th }}$ ed. Harvey Miller Publishers Oxford University Press.pp: 175.

21. Szaleczky, E.; Prechl, J.; Feber, J. \& Somogyi, A. (1999). Alterations in enzymatic antioxidant defense in diabetes mellitus a rational approach. Postgrad Med J. 75: 13-17.

22. Welch, W.J.; Tojo, A. \& Wilcox, C.S. (2000). Roles of No and oxygen radicals in tubuloglomerular feed back in SHR. Am J Physiol Renal Physiol.278:F769-F776.

23. Ward, N.C.; Rivera, J.; Hodgson, J.; Puddey, I.B.; Beilin, L.; Falck, J.R. \& Croft, K.D. (2004). Urinary 20-hydroxy eicosatetraenoic acid is associated with endothelial dysfunction in human. Circulation, 110(4):438443.

24. Zou, A.P.; Li, N. \& Cowley, A.W. (2001). Production and action of superoxide in the renal medulla. Hypertension, 37:547-553.

25. Schnachenberg,

C.G.

(2002). Physiological and Pathological roles of Oxygen radicals in the renal microvasculature. $A M \quad J$ Physiol Regul Integr Comp Physiol, 282: R 335-R 342.

26. Hunt, J. V.; Dean, R.T. \& Wolff, S.P. (1988). Hydroxyl radical production and autoxidation glycosylation: Glucose autoxidation as the cause of protein damage in the experimental glycation model of diabetes mellitus and ageing. Biochem J.256 (1): 205-212. 
التعقيدات المرضية الكلوية الحادة الناجمة عن داء السكر المستحث تجريبياً

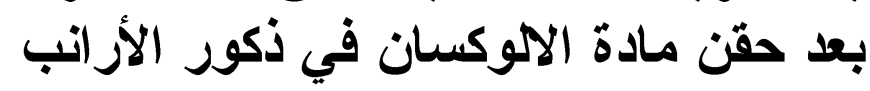

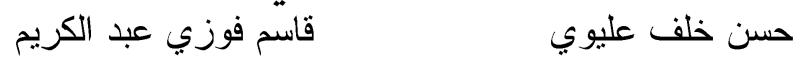

كلية الطب البيطري / جامعة القادسية كلية الصيدلة / جامعة البصرة

\section{الخلاصة}

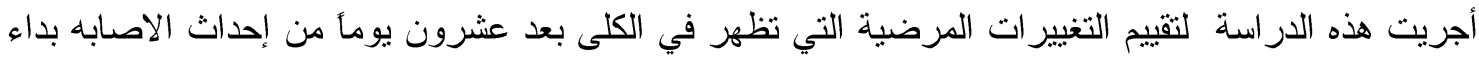

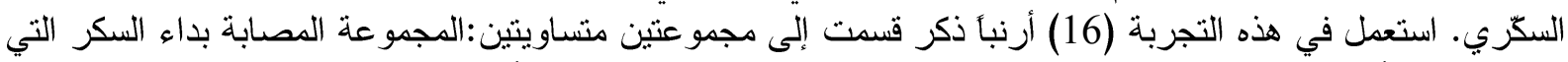

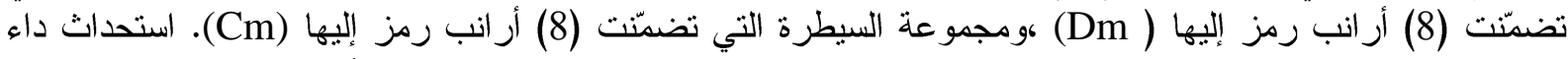

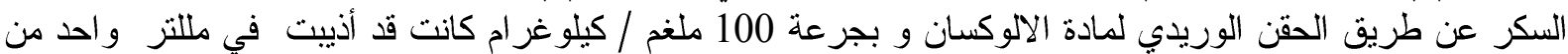

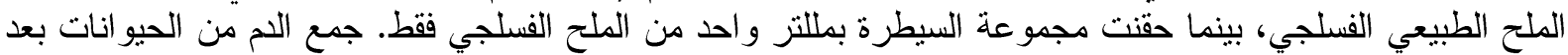

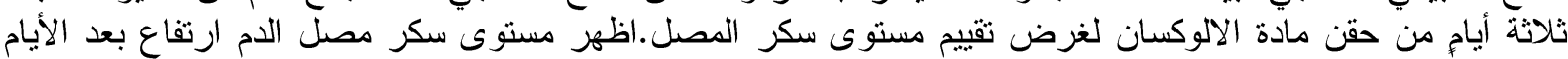

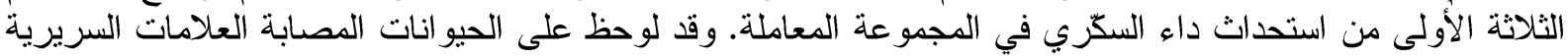

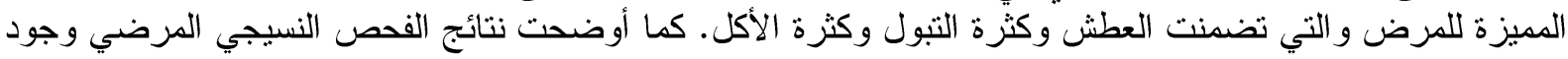

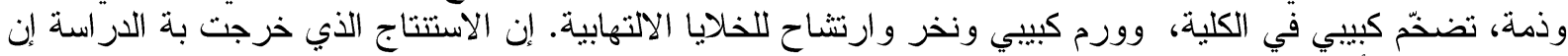

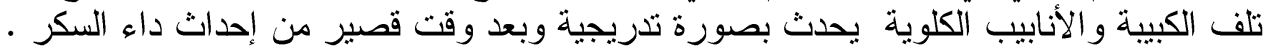

